\title{
Self-assembly of tholins in environments simulating Titan liquidospheres: Implications for formation of primitive coacervates on Titan
}

Jun Kawai ${ }^{1}$, Seema Jagota ${ }^{2}$, Takeo Kaneko ${ }^{1}$,Yumiko Obayashi ${ }^{1}$, Yoshitaka Yoshimura ${ }^{3}$, Bishun N. Khare $^{2}$, David W. Deamer ${ }^{4}$, Christopher P. McKay ${ }^{2}$, Kensei Kobayashi ${ }^{1}$

${ }^{1}$ Department of Chemistry and Biotechnology, Yokohama National University, Hodogaya-ku, Yokohama 240-8501, Japan

e-mail: kawai_jun_jy@ynu.ac.jp j_kawai0908@hotmail.com

${ }^{2}$ NASA Ames Research Center, Moffett Field, CA 94035-1000, USA

${ }^{3}$ Department of Agriculture, Tamagawa University, Machida, Tokyo 194-8600, Japan

${ }^{4}$ Jack Baskin School of Engineering, University of California, Santa Cruz 95064-1077, USA

\begin{abstract}
Titan, the largest satellite of Saturn, has a thick atmosphere containing nitrogen and methane. A variety of organic compounds have been detected in the atmosphere, most likely produced when atmospheric gases are exposed to ultraviolet light, electrons captured by the magnetosphere of Saturn, and cosmic rays. The Cassini / Huygens probe showed that the average temperature on the surface of Titan is $93.7 \mathrm{~K}$, with lakes of liquid ethane and methane. Sub-surface mixtures of liquid ammonia and water may also be present. We have synthesized complex organic compounds (tholins) by exposing a mixture of nitrogen and methane to plasma discharges, and investigated their interactions with several different liquids that simulate Titan's liquidosphere. We found that coacervates formed when tholins were extracted in non-polar solvents followed by exposure to aqueous ammonia solutions. The results suggest that coacervates can self-assemble in Titan's liquidosphere which have the potential to undergo further chemical evolution. Similar processes are likely to occur in the early evolution of habitable planets when tholin-like compounds undergo phase separation into microscopic structures dispersed in a suitable aqueous environment.
\end{abstract}

Key words: Titan, Tholin, self-assembly, coacervates, liquidosphere. 


\section{Introduction}

Titan is Saturn's largest satellite with a diameter is $5150 \mathrm{~km}$, and is known to have a dense atmosphere in contact with liquids on its surface (Lunine and Atreya, 2008). The atmospheric pressure at the surface is about $1500 \mathrm{hPa}$ at a temperature of $94 \mathrm{~K}$ (Samuelson et al., 1981; Lindal et al., 1983). The main component of the atmosphere is nitrogen, with smaller amounts of methane and ethane. Voyager's infrared interferometer spectrometer also detected traces amounts of ethane $\left(\mathrm{C}_{2} \mathrm{H}_{4}\right)$, acetylene $\left(\mathrm{C}_{2} \mathrm{H}_{2}\right)$, propane $\left(\mathrm{C}_{3} \mathrm{H}_{8}\right)$, hydrogen cyanide $(\mathrm{HCN})$, acetonitrile $\left(\mathrm{CH}_{3} \mathrm{CN}\right)$, cyanoacetylene $(\mathrm{CHCCN})$ and other diverse organic compounds in Titan's atmosphere (Hanel et al., 1981; Kunde et al., 1981; Maguire et al., 1981). In 1995, the Cassini spacecraft was launched by NASA and ESA to explore the Saturn system, and continues to return remarkably detailed images of Saturn and its satellites. In 2005, the Huygens probe separated from Cassini and descended through the atmosphere to Titan's surface. During descent, a gas chromatograph-mass spectrometer (GC/MS) analyzed atmospheric gases and detected $\mathrm{HCN}$ and $\mathrm{NH}_{3}$ after pyrolysis of captured mist particles (Israel et al., 2005).

Syntheses of organic material in simulated Titan atmosphere were first performed by Sagan and Khare (1979) who irradiated mixtures of nitrogen and methane with ultraviolet light and electrical discharge. A viscous brown organic polymer formed, which they named tholin after the Greek word for 'muddy'. The tholin was pyrolyzed and the products were analyzed with a gas chromatograph-mass spectrometer (Py-GC/MS). A variety of aliphatic and aromatic hydrocarbons, nitriles and nitrogen-containing compounds such as pyrrole and pyridine were detected after pyrolysis at $900^{\circ} \mathrm{C}$. It was suggested that tholins were kerogen-like substances having complex structures. The initial observations were followed by later studies in which a variety of gas mixtures were irradiated with different energy sources and the products analyzed (Khare et al., 1986; Sagan et al., 1993; Ehrenfreund et al., 1995; Coll et al., 1999). (See Table 1 for a list of relevant publications.)

Hydrocarbon lakes on the surface on Titan were first predicted by a photochemical model (Lorenz, 1994). The Huygens probe revealed that Titan's surface temperature was 93.7K (Fulchignoni et al., 2005), at which ethane and methane can remain liquid, and the Cassini radar observations showed that there are lakes composed of hydrocarbons (mainly liquid ethane and methane) at both high and low latitudes (Stofan et al, 2007; Brown et al., 2008; Griffith et al., 2012). Furthermore, if water ice on the surface of Titan is melted by a meteorite strike, as suggested by computer simulations, a liquid water lake would remain for $10^{2} \sim 10^{4}$ years (O'Brien, et al., 2005). Over the $10^{8}$ years history of Titan, it is estimated that $10^{22} \mathrm{~kg}$ of carbonaceous chondrites have delivered organic compounds to its surface, including possible lakes (Jones and Lewis 1987). Biologically important elements such as P, S, K and Na are contained in C1 chondrites (Anders and Grevesse 1989), and would also be supplied to Titan's liquidospheres.

Ammonia frost has been observed on the surface of Titan (Nelson et al, 2009), and the existence of sub-surface ammonia-water solutions was suggested by simulation models (Grasset et al., 2000; 
Tobie et al., 2005).The $\mathrm{pH}$ of an ammonia-water solution with $15 \mathrm{wt} \%$ ammonia is 11.4 (Engel et al., 1994, Fortes, 2000) but the $\mathrm{pH}$ is expected to decrease at high pressure to a value closer to $\sim 10.5$ (Krauskopf and Bird 1995). Given that both tholins and a liquidosphere are present on Titan, what happens when tholins come into contact with liquids like ammonia-water? There have been several reports on the solubility of tholins. McKay (1996) synthesized tholins by spark discharges in a 9:1 mixture of $\mathrm{N}_{2}$ and $\mathrm{CH}_{4}$ and found that they could be dissolved in water, methanol and ethanol. Coll et al. (1999) examined the solubility of tholins formed by direct current (DC) glow discharges in a gas mixture of $\mathrm{N}_{2} / \mathrm{CH}_{4}(98: 2)$, and found that they were soluble in nitriles such as acetonitrile, isobutyronitrile, propionitrile and benzonitrile. When a mixture of $\mathrm{CH}_{4}$ and $\mathrm{N}_{2}$ was exposed to an alternating current (AC) electrical discharge at $195 \mathrm{~K}$, the products were soluble in a 1:1 methanol/acetonitrile mixture which was used for ESI-MS and FT-ICR-MS measurements in order to measure their molecular weights and elemental compositions (Sarker et al., 2003; Smogyi et al., 2005). He et al. (2012a, b) synthesized tholins by a similar procedure but with ${ }^{13} \mathrm{C}$ and ${ }^{15} \mathrm{~N}$ isotopic labeling, then dissolved them in DMSO to investigate structures of tholins by nuclear magnetic resonance (NMR) spectroscopy.

The presence of a liquidosphere on Titan containing an admixture of tholins suggests that it would be worth investigating how tholins behave in aqueous dispersons. Trainer et al. (2006) irradiated a gas mixture composed of nitrogen and methane, and observed spherical particles several nm in diameter by transmission electron microscopy. However, there have been no studies of tholins exposed to conditions simulating an ammonia-water ocean. The purpose of the present study is to examine self-assembly properties of tholins under these conditions. Both hydrophilic and hydrophobic liquids are presumed to be present on Titan, so we investigated solubility of tholins in non-polar solvents and possible self-assembly properties in a polar ammonia-water solvent. Hexane and chloroform were used in place of methane and ethane because they can exist as liquid at a room temperature. Solutions of tholins in these solvents were analyzed by FT-IR and fluorescence spectrometry. The tholin fractions that dissolved in organic solvents were exposed to an ammonia-water solvent system and were observed to self-assemble into coacervates.

\section{Materials and Methods}

\section{Chemicals}

Deionized water was further purified with Milli-Q to remove both inorganic ions and organic contaminants. A gas mixture of $\mathrm{CH}_{4} / \mathrm{N}_{2}$ (10/90) was purchased from Matheson Tri-Gas / Aeris (USA). All other chemicals used were analytical grade. Glassware and a metal rod were heated in high-temperature oven at $500^{\circ} \mathrm{C}$ to eliminate possible organic contaminants.

\section{Synthesis of Tholins}

Tholins was synthesized by plasma discharge into the gas mixture at 1 Torr (133 Pa) for 72 hours. 
The discharge device at NASA Ames was RFX-600 with a glass slide attached to the lower electrode. The chamber was flushed with oxygen to clean it before the gas mixture was injected. After plasma discharge for 72 hours, the products on the plate were scraped off with a metallic rod. The collected tholins were dissolved in either non-polar solvents such as hexane and chloroform, or dispersed in an ammonia-water solution, followed by analysis.

\section{$F T-I R$}

FT-IR spectra of tholin samples in chloroform $\left(1 \mathrm{mg} \mathrm{mL}^{-1}\right)$ were obtained with a Nicolet Nexus 670 spectrometer over the range of 4000 to $500 \mathrm{~cm}^{-1}$ with a resolution of $1 \mathrm{~cm}^{-1}$. After filtration through a PTFE membrane filter (pore size; $2 \mu \mathrm{m}$, Varian Inc.), the filtrate was completely dried, then $50 \mu \mathrm{L}$ of chloroform was added. Twenty $\mu \mathrm{L}$ of the solution was dried on a $\mathrm{KBr}$ window (PIKE Technologies). The FT-IR sample chamber was constantly purged with dry air to remove moisture.

\section{Fluorescence Spectrometry}

Tholin samples were dispersed in $10 \mathrm{mM} \mathrm{NH}_{4} \mathrm{OH}$ at a concentration of $0.67 \mathrm{mg} \mathrm{mL}^{-1}$. The dispersion was filtered through cellulose acetate filter (pore size; $0.2 \mu \mathrm{m}$, ADVANTEC), and the filtrate was put in a quartz cell (Scientific Ltd.). Three-dimensional fluorescence spectra were measured with a JASCO FP-6300 fluorescence spectrometer. Excitation and emission were scanned over the range of 220 - $600 \mathrm{~nm}$ at $1 \mathrm{~nm}$ intervals with the excitation slit set at $20 \mathrm{~nm}$.

\section{Fluorescence Microscopy}

A Zeiss Axiovert 135M fluorescence microscope was used to monitor possible self-assembly properties. Tholin samples dissolved either in chloroform or hexane were dried on a clean glass slide, followed by addition of $10 \mu \mathrm{L} \mathrm{NH}_{4} \mathrm{OH}$ and a cover slip. The initial drying process was designed to allow self-assembly of tholins into aggregates which could then be visualized. The same field was observed by differential interference contrast (DIC) mode and in fluorescence mode with a filter (excitation: 365BP25) and a dichroic mirror (370). Images were taken with a digital camera (Canon EOS Kiss X3).

\section{Results}

\section{Solubility of tholins}

The samples described here were synthesized in gas mixtures either at high pressure (1 Torr, 133 $\mathrm{Pa}$ ) or low pressure (0.2 Torr, $26 \mathrm{~Pa}$ ). Hereafter the former product is referred to as HP tholins and the latter as LP tholins. Tholins could be partially dissolved in chloroform to produce a pale yellow-orange solution, but solubility of tholins in hexane was quite low.

\section{FT-IR}

Infrared spectra of chloroform soluble fractions of HP and LP tholins are shown in Fig. 1a and b. 
The bands at 3324-3366 $\mathrm{cm}^{-1}$ (Fig. 1a) and at $3355 \mathrm{~cm}^{-1}$ (Fig. 1b) were assigned to stretching of N-H groups. Other bands at 3019, 2959, 2918 and $2849 \mathrm{~cm}^{-1}$ (Fig. 1a) and at 3019, 2962, 2918 and $2849 \mathrm{~cm}^{-1}$ (Fig. 1b) were assigned to stretching of $\mathrm{C}-\mathrm{H}$ groups. In addition, tholins gave peaks of unsaturated bonds such as $\mathrm{C}=\mathrm{C}$ and $\mathrm{C}=\mathrm{N}$ bonds $\left(1600-1670 \mathrm{~cm}^{-1}\right)$ and $\mathrm{C} \equiv \mathrm{N}$ bond $\left(2200-2260 \mathrm{~cm}^{-1}\right)$. LP tholins gave stronger peaks of $-\mathrm{NH}$ and $-\mathrm{CN}$ groups compared the chloroform-soluble fraction of HP tholins.

\section{Fluorescence Spectrometry}

Three-dimensional fluorescence spectra of ammonia-water extracted of HP tholins and LP tholins are similar (Fig. 2a and b). Maximum excitation and emission wavelengths of the HP tholins were $346 \mathrm{~nm}$ and $426 \mathrm{~nm}$, respectively, and those of LP tholins were $345 \mathrm{~nm}$ and $428 \mathrm{~nm}$.

\section{Microscopy}

We used DIC microscopy and fluorescence microscopy to investigate the behavior of tholins exposed to aqueous ammonia solutions. After tholin samples were dried from chloroform or hexane solutions onto glass slides, the HP tholins adhered to the slide as brown particles, whereas LP tholins were black. Following addition of $10 \mathrm{mM} \mathrm{NH}_{4} \mathrm{OH}$, the tholins dried from chloroform solutions assembled into spherical structures in the range of 1-15 $\mu \mathrm{m}$ diameters. Tholins dried from hexane solutions produced somewhat larger and more complex globular structures (Fig. 3). Because chloroform is more polar than hexane, the chloroform extract of tholins contained higher concentrations of polar molecules, while hexane extracts contained more non-polar molecules. The difference in polarity probably accounts for the observed variations in the self-assembled structures.

\section{Discussion}

In order to understand the self-assembly properties of tholins, it is essential to have general knowledge of their synthesis and composition. Possible energy sources available on Titan include ultraviolet light, electrical discharge and cosmic rays. Ultraviolet light is not absorbed by molecular nitrogen gas and therefore does not photochemically activate a nitrogen-methane mixture (Yung et al., 1984), so synthesis of organic compounds containing nitrogen requires higher energy sources such as electrical discharges.

A variety of two to four ring polycyclic aromatic hydrocarbons (PAHs) were identified by two step laser mass spectrometry ( $\mathrm{L}^{2} \mathrm{MS}$ ) in tholins that were formed from a $90 \% \mathrm{~N}_{2} / 10 \% \mathrm{CH}_{4}$ gas mixture by direct current (DC) discharges (Sagan et al., 1993). Ehrenfreund et al. (1995) synthesized tholins by plasma discharge of a mixture of $90 \%$ nitrogen and $10 \%$ methane at $0.2 \mathrm{hPa}$, and characterized the products by Py-GC/MS. They reported that tholins were composed of hydrogen cyanide, acetonitrile, long-chained unsaturated nitriles, aromatic compounds such as benzene and toluene, and nitrogen-containing heteroaromatics such as pyridine and pyrrole. The tholins had peaks at $14 \mathrm{~m} / \mathrm{z}$ intervals, suggesting that a major component of tholins were methylene groups $\left(-\mathrm{CH}_{2}-\right)$. Because 
Py-GC/MS analysis provides such rich information about chemical composition, the Huygens probe loaded an Aerosol Collector and Pyrolyser (ACP) for in situ characterization of aerosols in Titan's atmosphere.

Imanaka et al. (2004) analyzed the tholins synthesized by plasma discharge in a mixture of methane (10\%) and nitrogen (90\%) at varying pressures $(13-2300 \mathrm{~Pa})$, and reported that nitrogen-containing polycyclic aromatic compounds more easily formed at the lower pressure. Somogyi et al. (2005) analyzed tholins synthesized by an alternating current (AC) electrical discharge in a gas mixture of $95 \%$ nitrogen and 5\% methane, and the resulting tholins were analyzed by high resolution Fourier transform ion cyclotron resonance mass spectrometry (FT-ICR MS). These authors reported that tholins were complex molecules composed of carbon, hydrogen and nitrogen, with molecular weights in the range of several hundred daltons. Szopa et al. (2006) analyzed atoms and radicals in the discharged plasma with optical emission spectroscopy (OES). The emission spectra showed that atoms and radicals produced by discharges were growing into particles in the plasma. McGuigan et al. (2006) analyzed the tholins by pyrolysis-two-dimensional gas chromatography - time of flight mass spectrometry (GC $\times$ GC-TOF-MS). They identified several organic compounds of nitriles, pyrroles, hydrocarbons, benzenes and PAH compounds. Polycyclic aromatic hydrocarbons (PAHs) may also have a significant role in the synthesis of tholins (Wilson and Atreya, 2003).

Tholins have also been characterized with several techniques including estimation of their molecular weights. Gas mixtures of $\mathrm{CH}_{4}$ and $\mathrm{N}_{2}(1 \mathrm{mbar}, 2: 98$ or 10: $90 \mathrm{v} / \mathrm{v})$ were irradiated with a radio frequency plasma discharge. The products were dissolved in methanol or toluene, and identified by atmospheric pressure photoionization (APPI) - hybrid quadrupole time-of-flight mass spectrometry (QTOFMS) with a tandem collision induced dissociation (CID) method. The spectra showed peak clusters with 13-14 m/z intervals in $50-800 \mathrm{~m} / \mathrm{z}$, area (Carrasco et al., 2009). Elementary analysis of tholins produced by RF discharge from 13 - $2300 \mathrm{~Pa}$ gas mixtures of $\mathrm{CH}_{4}$ and $\mathrm{N}_{2}$ (10: $90 \mathrm{v} / \mathrm{v}$ ) showed that the $\mathrm{C} / \mathrm{N}$ ratio was $1.45-2.76$ (Imanaka et al., 2004). These previous analytical results suggested that Titan tholins we synthesized would have hydrophobic groups that were large enough to undergo self-assembly.

Finally, it is significant that biomolecules used by terrestrial life have also been detected in tholins synthesized when a gas mixture of $10 \%$ methane and $90 \%$ nitrogen at 0.2 mbar was exposed to direct current (DC) discharge. The products were hydrolyzed with $6 \mathrm{M} \mathrm{HC1}$, then derivatized with N-trifluroacetyl isopropyl esters, and 16 amino acids were identified (Khare et al., 1986). In more recent studies, tholins were synthesized by radio frequency (RF) discharge in a gas mixture $\left(\mathrm{N}_{2}: \mathrm{CH}_{4}=98: 2\right)$, hydrolyzed in $2 \mathrm{M} \mathrm{HCl}$, and derivatized with N-tert-butyldimethyl-silyl-N-methyltrifluoroacetamide (MTBSTFA) for GC/MS. A variety of organic compounds including amino acids and carboxylic acids were identified (Nguyen et al., 2008). Neish et al. (2008, 2009, 2010) also synthesized tholins by a procedure similar to that reported by Sarker et al. (2003) and Smogyi et al. (2005), and dissolved the tholins in ammonia solution at $253 \mathrm{~K}$ or $293 \mathrm{~K}$. They identified almost all amino acids except sulfur-containing species such as cysteine and methionine and nucleobases such as adenine, guanine, 
thymine, cytosine and uracil in the solution without acid-hydrolysis. Horst et al. (2012) also identified various organic compounds including amino acids and nucleotide bases without hydrolysis for tholins synthesized according to Szopa et al. (2006), Nguyen et al. (2008) and Carrasco et al. (2009).

\section{Fluorescence properties of tholins}

Hodyss et al. (2004) synthesized tholins by alternating current (AC) electrical discharge in gas mixtures of $\mathrm{CH}_{4}$ and $\mathrm{N}_{2}(1 \mathrm{mbar}, 2: 98$ or $10: 90 \mathrm{v} / \mathrm{v})$ at $195 \mathrm{~K}$. When the tholins were dissolved in acetonitrile, the fluorescence excitation spectra showed a peak at $410 \mathrm{~nm}$, with an emission peak at 471 $\mathrm{nm}$. When water was used, tholins showed complex fluorescence spectra with multiple peaks. The effects of solvents, temperature and synthesis conditions had only minor effects on the excitation and emission wavelengths. From the Py-GC/MS results, it was suggested that tholins synthesized by direct current (DC) and radio frequency (RF) discharge contain aromatic compounds such as benzene, toluene and heterocyclic compounds like pyrrole and pyridine (Ehrenfreund et al., 1995; McGuigan et al., 2006). It seems likely that the fluorescence characteristics of our tholins were mainly due to the presence of aromatic hydrocarbon groups and heterocyclic groups. Since the tholins had fluorescence, it was possible to image self-assembled tholin structures by fluorescence microscopy.

\section{Mechanism of self-assembly of amphiphilic molecules}

Tholins are composed of $\mathrm{C}$ (carbon), $\mathrm{N}$ (nitrogen), $\mathrm{H}$ (hydrogen) present in the original gas mixture, but lack $\mathrm{O}$ (oxygen). Most hydrophilic organic compounds have O-containing groups such as hydroxyl $(-\mathrm{OH})$ and carboxyl groups $(-\mathrm{COOH})$, but they cannot be expected to be present in our tholins. For this reason amino or imino groups are likely to be hydrophilic groups in Titan tholins. In fact, FT-IR spectra of chloroform solutions of HP and LP tholins revealed the presence of both hydrophilic amine groups and hydrophobic alkyl groups. In preliminary experiments, we confirmed amphiphilic properties of tholins by spreading a few microliters of a chloroform solution of HP tholin on the air-water interface of a Langmuir trough. The tholin readily spread to form a film at the interface which produced a measureable surface pressure. When the film was compressed it went through a transition to a solid phase. This result clearly indicates that tholins have surface active properties expected of an amphiphile and are likely to undergo self-assembly into more complex structures.

Self-assembly of ordinary amphiphilic compounds such as fatty acids and phospholipids is related to the length of carbon chains in the molecule. Amphiphiles with hydrophobic chains more than eight carbons in length form micelles can assemble into vesicles bounded by bilayer membranes (Apel et al., 2002). Long alkyl chains with 13-23 carbons were detected in CM2 chondrites by gas chromatography (Studier et al. 1968; Smith and Kaplan, 1970; Ander et al. 1973). FT-IR spectra showed that the extracted molecules had both hydrophilic groups such as carboxyl and hydroxyl groups and hydrophobic group such as alkyl groups. If sufficiently long amphiphilic molecules are present, it is likely that they will undergo self-assembly into more complex structures. For instance, Deamer and Pashley (1989) demonstrated that amphiphilic components in chloroform-methanol extracts from the 
Murchison meteorite produced membranous vesicles and coacervates.

However, because tholins are polymers of varying length and do not have long hydrocarbon chains, self-assembly into true membranes cannot occur. Instead the self-assembled structures are better described as coacervates. These could be observed as self-assembled microspheres when an ammonia solution was added to tholin films dried from chloroform solutions onto glass slides. If hexane-soluble tholins were used instead, the tholins assembled into more complex aggregates with small fluorescent particles on their surfaces (Fig.3). The differences are most likely due to differential solubility of tholin components in solvents having more or less polar character. For instance, the solubility of tholins is higher in polar solvent such as ethanol $(\varepsilon=24)$ than that in non-polar solvents such as hexane $(\varepsilon=1.9)$, toluene $(\varepsilon=2.4)$ and benzene $(\varepsilon=2.3)$. In other less polar solvents, chloroform has a larger dielectric constant $(\varepsilon=4.8)$ than hexane, and tholins are more soluble in chloroform than in non-polar solvents such as hexane (McKay, 1996; Carrasco et al., 2009).

Table 1 summarizes characteristics of organic solvents, and Table 2 shows characteristics of molecules found in Titan environments. If Titan lakes are composed of liquid methane and ethane, our results suggest that only small amounts of tholins could dissolve in them. However, if Titan lakes have more polar molecules as minor constituents, solubility of tholins would be markedly increased. Some of the compounds shown in Table 3 do exist in Titan atmosphere, and those with oxygen atoms would increase dielectric constant of Titan's lakes if they are components. It would be interesting to examine the solubility and behavior of Titan tholins in actual low temperature environments like liquid methane (boiling point $-161.6^{\circ} \mathrm{C}$, melting point $-182.5^{\circ} \mathrm{C}$ ) and ethane (boiling point $-89^{\circ} \mathrm{C}$, melting point $-172^{\circ} \mathrm{C}$ ) lakes.

\section{Coacervates}

Formation of self-assembled structures is an important first step of chemical evolution which separates an internal molecular system from the external environment. Oparin $(1957,1976)$ discussed the relevance of coacervates to the origin of life. Coacervates are defined as aggregates formed by colloidal macromolecules in aqueous solvent systems. In his pioneering studies, Oparin had little knowledge of the actual macromolecular composition of cytoplasm, so he used polymers such as gum arabic and gelatin to produce coacervates. More recent studies employed polymers of amino acids, such as the proteinoid microspheres described by Fox et al. (1963). Egami (1974) proposed that transition metal ions in seawater may have played a significant role such as catalysis during chemical evolution. Coacervates called marigranules can be produced when a mixture of amino acid is maintained in seawater at $105^{\circ} \mathrm{C}$ for 4 weeks (Yanagawa and Egami, 1981). The sea water was modified by addition of transition metal ions to concentrations simulating those estimated to be present in early oceans.

The self-assembled structures formed from the Titan tholins described here are best defined as coacervates. The fact that they are fluorescent when activated by near-UV wavelengths is significant, because it is possible that the energy absorbed from UV photons could drive further chemical evolution by photochemical processes. Future studies directed toward this possibility are likely to be fruitful. 


\section{The significance of the results for astrobiology}

The results reported here show that tholins synthesized in simulated upper atmosphere of Titan could undergo self-assembly in ammonia-water solutions to form coacervates. In our simulation experiments, the synthesized tholins were extracted with hexane or chloroform and then $\mathrm{NH}_{3} / \mathrm{H}_{2} \mathrm{O}$ solution was added. A possible scenario of self-assembly processes on Titan is as follows: complex organic compounds (tholins) are formed in Titan's atmosphere by energy sources such as high-energy electrons, the equivalent of the plasma discharge used in our simulations. Then Titan tholins are accumulated onto the Titan surface, and then can be processed with methane rain, or liquid methane and ethane in lakes. The dissolved moiety of tholins then comes into contact with ammonia-water jets associated with cryovolcanic activity and assemble into the coacervates as found in our simulations.

Assuming that the coacervates represent the first steps in evolution toward living systems, is it possible that microbial organisms could emerge and thrive in Titan's environment? For instance, Fortes (2000) estimated that Titan's underground sea is composed of $15 \%$ ammonia aqueous solution, with a $\mathrm{pH}$ of 11.5. Some terrestrial microbes can in fact survive in such highly alkaline solutions. Alkaliphiles isolated from water samples in a gold mine near Carletonville, South Africa can grow at $\mathrm{pH} \sim 12.5$ (Takai et al., 2001), so the $\mathrm{pH}$ of subsurface water in Titan does not prohibit the emergence of life. Another interesting question is whether life might be able to adapt to non-polar hydrocarbon solvents. In this regard, it is interesting that microbial populations have been found in the Pith Lake of Trinidad and Tobago, where the liquid mostly consists of asphaltenes (Schulze-Makuch et al., 2011). It would be interesting to determine whether such microorganisms could use tholins as a source of carbon, fixed nitrogen and chemical energy, thereby relating the requirements of terrestrial life to possible life in the Titan liquidosphere. There is in fact a precedent for such a study, because Mautner et al. (1995) demonstrated that aqueous extracts of the Murchison meteorite provided a sufficent nutrient source for a variety of microorganisms.

\section{Acknowledgements}

We would like to thank the scientists at NASA Ames Research Center for their cooperation in sample collection. Dr. Hiroshi Imanaka is acknowledged for useful comments of plasma discharge. Drs Delphine Nna Mvondo and Patrick Wilhite are appreciated for helpful discussions of infrared spectra.

\section{References}

Anders, E., Hayatsu, R. \& Studier, M. H. (1973). Science 182, 781-790.

Anders, E., \& Grevesse, N. (1989). Geochim. Cosmochim. Acta 53, 197-214.

Apel, C. L., Deamer, D.W. \& Mautner, M. N. (2002). Biochimica et Biophysica Acta 1559, 1-9.

Brown, R. H., Soderblom, L. A., Soderblom, J. M., Clark, R. N., Jaumann, R., Barnes, J. W., Sotin, C., 
Buratti, B., Baines, K. H. \& Nicholson, P. D. (2008). Nature 454, 607-610.

Carrasco, N., Schmitz-Afonso, I., Bonnet, J-Y., Quirico, E., Thissen, R., Dutuit, O., Bagag, A., Laprevote, O., Buch, A., Giulani, A., Adande, G., Ouni, F., Hadamcik, E., Szopa, C. \& Cernogora, G. (2009). Revisited. J. Phys. Chem. A 113, 11195-11203.

Coll, P., Coscia, D., Smith, N., Gazeau, M. C., Ramõrez, S.I., Cernogor, G., Israel, G. \& Raulin, F. (1999). Planetary and Space Science 47, 1331-1340.

Deamer, D. W. \& Pashley P.M. (1989). Amphiphilic components of the Murchison carbonaceous chondrite: Surface properties and membrane formation. Origins of Life and Evolution of the Biosphere. 19, 21-38.

Ehrenfreund, P., Boon, J. J., Commandeur, J., Sagan, C., Thompson, W. R. \& B. N. Khare (1995). Adv. Space Res. 15(3), 335-342.

Egami, F. (1974). Journal of Molecular Evolution 4 (2), 113-120.

Engel, S., Lunine, J. I. \& Norton, D. L. (1994). J. Geophys. 99, 3745-3752.

Fulchignoni, M., Ferri, F., Angrilli, F., Ball, A. J., Bar-Nun, A., Barucci, M. A., Bettanini, C., Bianchini, G., Borucki, W., Colombatti, G., Coradini, M., Coustenis, A., Debei, S., Falkner, P., Fanti, G., Flamini, E., Gaborit, V., Grard, R., Hamelin, M., Harri, A. M., Hathi, B., Jernej, I., Leese, M. R., Lehto, A., Lion P. F., López-Moreno, J. J., Mäkinen, T., McDonnell, J. A. M., McKay, C. P., Molina-Cuberos, G., Neubauer, F. M., Pirronello, V., Rodrigo, R., Saggin, B., Schwingenschuh, K., Seiff, A., Simões, F., Svedhem, H., Tokano, T., Towner, M. C., Trautner, R., Withers, P. \& Zarnecki, J. C. (2005). Nature 438, 785-791.

Fortes, A. D. (2000). Icarus 146, 444-452.

Fox, S. W., Harada, K., Woods, K. R. \& Windsor, C. R. (1963). Archives of biochemistry 102 (3), 439-445.

Grasset, O., Sotin, C. \& Deschamps, F. (2000). Planet. Space Sci. 48, 617-636.

Griffith, C. A., Lora, J. M., Turner, J., Penteado, P. F., Brown, R. H., Tomasko, M. G., Doose, L. \& See, C. (2012). Nature 237, 486.

Hanel, R., Conrath, B., Flasar, F. M., Kunde, V., Maguire, W., Pearl, J., Pirraglia, J., Samuelson, R., Herath, L., Allison, M., Cruikshank, D., Gautier, D., Gierasch, P., Horn, L., Koppany, R. \& Ponnamperuma, C. (1981). Science 212,192-200.

He, C., Lin, G., Upton, K. T., Imanaka, H., Mark, A. \& Smith, M. A. (2012). J. Physical Chemistry 116, 4751-4759.

He, C., Lin, G., Upton, K. T., Imanaka, H., Mark, A. \& Smith, M. A. (2012). J. Physical Chemistry 116, 4760-4767.

Hodyss, R., McDonald, G., Sarker, N., Smith, M. A., Beauchamp, P. M., Beauchamp J. L. (2004). Icarus 171, 525-530

Imanaka, H., Khare, B. N., Elsila, J. E., Bakes, E. L.O., McKay, C. P., Cruikshank, D. P., Sugita, S., Matsui, T. \& Zare, R. N. (2004). Icarus 168, 344-366.

Horst, S. M., Yelle, R. V., Buch, A., Carrsco, N., Cernogora, G., Dutuit, O., Quirico, E., 
Sciamma-O’Brein, E., Smith, M. A., Somogyi, A., Szopa, C., Thissen, R. \& Vuitton, V. (2012). Astrobiology 12, 809-817.

Israel, G., Szopa, C., Raulin, F., Cabane, M., Niemann, H. B., Atreya, S. K., Bauer, S. J., Brun, J.F., Chassefière, E., Coll, P., Condé, E., Coscia, D., Hauchecorne, A., Millian, P., Nguyen, M.J., Owen, T., Riedler, W., Siguier, R. E., Samuelson, J.M., Steller, M., Sternberg, R. \& Vidal-Madjar, C. (2005). Nature 438, 796-799.

Jones, T. D. \& Lewis, J. S. (1987). Icarus 72, 381-398.

Khare, B. N., Sagan, C., Ogino, H., Nagy, B., Er, C., Schram, K. H. \& Arakawa, E.T. (1986). Icarus 68, 176-184.

Krauskopf, K. B. \& Bird D. K. (1995) Introduction to Geochemistry, 3rd ed. McGraw-Hill, New York.

Kunde, V.G., Aikin, A.C., Hanel, R.A., Jennings, D.E., Maguire W.C. \& Samuelson, R.E. (1981). Nature 292, 686-688.

Lindal, G.F., Wood, G.E., Hotz, H.B., Sweetnam, D.N., Eshelman, V.R. \& G.L. Tyler (1983). Icarus 32, 413-430.

Lorenz, R. D. (1994). Planet. Space Sci. 42 (1), 1-4.

Lunine, J. I. \& Atreya, S.K. (2008). Nature Geoscience 1, 159-164.

Maguire, W.C., Hanel, R.A., Jennings, D.E., Kunde, V.G. \& Samuelson, R.E. (1981). Nature 292, 683-686.

Mautner, M.N., Leonard, R. \& Deamer, D.W. (1995). Meteorite organics in planetary environments: Hydrothermal release, surface activity and microbial utilization. Planet. Space Sci. 43: 139-147.

McGuigan, M., Waite, J. H., Imanaka, H. \& Sacks, R. D. (2006). Journal of Chromatography A 1132, 280-288.

McKay, C.P. (1996). Space Sci. 44, 741-747.

Nguyen, M.-J., Raulin, F., Coll, P., Derenne, S., Szopa, C., Cernogora, G., Israe, G. \& Bernard J.-M. (2008). Advances in Space Research 42, 48-53.

Neish, C.D., Somogyi, Á., Imanaka, H., Lunine, J.I. \& Smith, M.A. (2008). Astrobiology 8 (2), $273-287$.

Neish, C.D., Somogyi, Á., Lunine, J.I.\& Smith, M.A. (2009). Icarus 201, 412-421.

Neish, C.D., Somogyi, Á., Lunine, J.I., and Smith, M.A. (2010). Astrobiology 10 (3), 337-347.

Nelson, R. M., Kampa, L.W., Matsona, D.L., Irwinb, P. G. J., Bainesa, K.H., Borytac, M.D., Leadera, F.E., Jaumannd, R., Smythea, W.D., Sotine, C., Clarkf, R.N., Cruikshankg, D.P., Drossarth, P., Pearli, J.C., Hapkej, B.W., Luninek, J., Combesl, M., Belluccim, G., Bibringn, J. P., Capaccionim, F., Cerronim, P., Coradinim, A., Formisanom, V., Filacchionem, G., Langevinn, R. Y., McCordo, T.B., Mennellap, V., Nicholsonq, P. D. \& Sicardy, B. (2009). Icarus 199, 429- 441.

O’Brien, D. P., Lorenz, R. D. \& Lunine, J.I. (2005). Icarus 173, 243-253.

Oparin, A.I. (1957) Origins of life on Earth. Edinburgh: Oliver and Boyd. ,495 pp.

Oparin, A.I., Orlovskii, A. F., Bukhlaeva, V.I.A. \& Gladilin, K.L. (1976). Dokl. Akad.Nauk SSSR 226, 972-974.

Riddick, J. A. \& Bunger, W. B. (1970) Techniques of Chemistry Volume II, Organic solvents physical 
properties and method of purification third edition.

Sagan, C. \& Khare, B. N. (1979). Nature 277, 102-107

Sagan, C., Khare, B. N., Thompson, W. R., McDonald, G. D., Wing, M. R., Bada, J. L., Vo-Dihn, T. \& Rakawa, E. T. (1993). Astrophys. J. 414, 399-405.

Samuelson, R. E., Hanel, R. A., Kunde, V. G. \& Maguire, W. C. (1981). Nature 292, 688-693.

Sarker, N., Somogy, A., Lunine, J. I. \& Smith, M. A (2003). Astrobiology, 3, 719-726.

Schulze-Makuch, D., Haque, S., de Sousa Anto, M. R., Hosein, R., Song, Y. C., Yang, J., Zaikova, E., Guinan, D. E., Lehto, H. J. \& Hallam S. J. (2011). Astrobiology 11 (3), 241-258.

Smith, J. K. \& Kaplan, J. R. (1970). Science 167 (3923), 1367-1370.

Somogyi, A., Oh, C., Smith, M. A. \& Lunine, J. I. (2005). J. Am. Soc. Mass Spectrom 16, 850-859.

Sotin, C., Jaumann, R., Buratti, B. J., Brown, R. H., Clark, R. N., Soderblom, L. A., Baines, K. H., Bellucci, G., Bibring, J. P., Capaccioni, F., Cerroni, P., Combes, M., Coradini, A., Cruikshank, D. P., Drossart, P., Formisano, V., Langevin, Y., Matson, D. L., McCord, T. B., Nelson, R. M., Nicholson, P. D., Sicardy, B., LeMouelic, S., Rodriguez, S., Stephan, K. \& Scholz, C. K. (2005). Nature 435, 786-789.

Stofan, E. R., Elachi C., Lunine, J. I., Lorenz, R. D., Stiles, B., Mitchell, K., Ostro, L. S., Soderblom, L., Wood, C., Zebker, H., Wall, S., Janssen, M., Kirk, R., Lopes, R., Paganelli, F., Radebaugh, J., Wye, L., Anderson, Y., Allison, M., Boehmer, R., Callahan, P., Encrenaz, P., Flamini, E., Francescetti, G., Gim, Y., Hamilton, G., Hensley, S., Johnson, W. T. K., Kelleher, K., Muhleman, D., Paillou, P., Picardi,G., Posa, F., Roth, L., Seu, R., Shaffer, S., Vetrella S. \& West, R (2007). Nature 445, 61-64.

Studier, M. H., Hayatsu, R. \& Anders, E. (1968). Geochimica et Cosmochimica Acta 32 (2), 151-173.

Szopa, C., Cernogora, G., Boufendi, L., Correia, J.-J. \& Coll, P. (2006). Planetary and Space Science 54 (4), 394-404.

Tobie, G., Grasset, O., Lunine, J. I., Mocquet, A. \& Sotin, C. (2005). Icarus 175, 496-502.

Takai, K., Moser, D. P. Onstott, T. C., Spoelstra, N., Pfiffner, S. M., Dohnalkova, A. \& Fredrickson, J. K. (2001). International Journal of Systematic and Evolutionary Microbiology 51, 1245-1256.

Trainer, M. G., Pavlov, A. A., DeWitt, H. L., Jimenez, J. L., McKay, C. P., Toon, O. B. \& Tolbert, M. A. (2006). PNAS, 103 (48), 18035-18042.

Wilson, E. H. \& Atreya, S. K. (2003). Planet Space Sci. 51, 1017-1033.

Yanagawa, H. \& Egami, F. (1980). Origin of Life, Proceeding of $3^{\text {rd }}$ ISSOL meeting and $6^{\text {th }}$ ICOL meeting.

Yung, Y. L., Allen, M. \& Pinto, J. P. (1984). Astrophys. J. Suppl. 292, 683-686. 

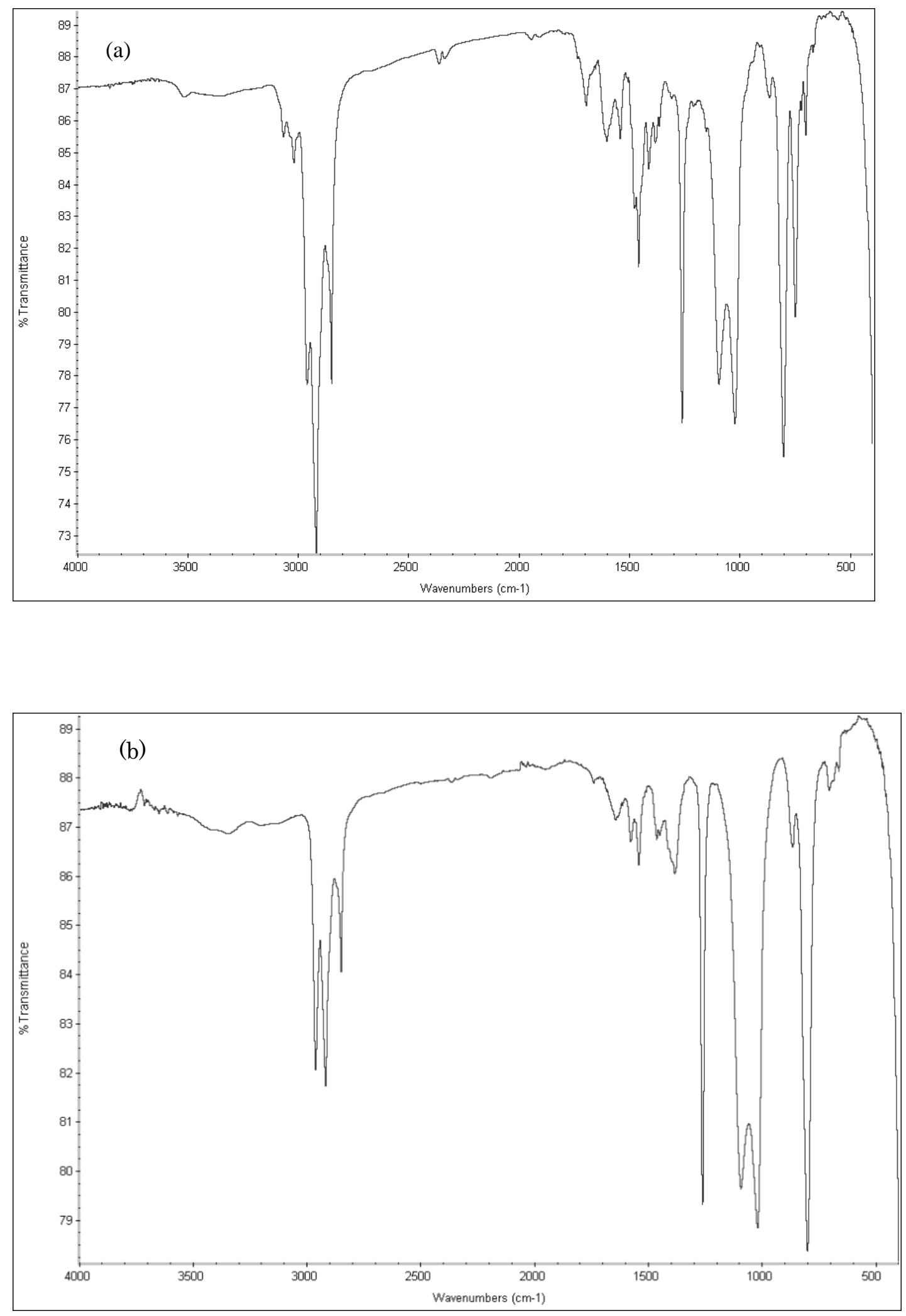

Fig. 1. FT-IR Spectra of HP (a) and LP (b) Tholin (Chloroform fraction) on KBr. 

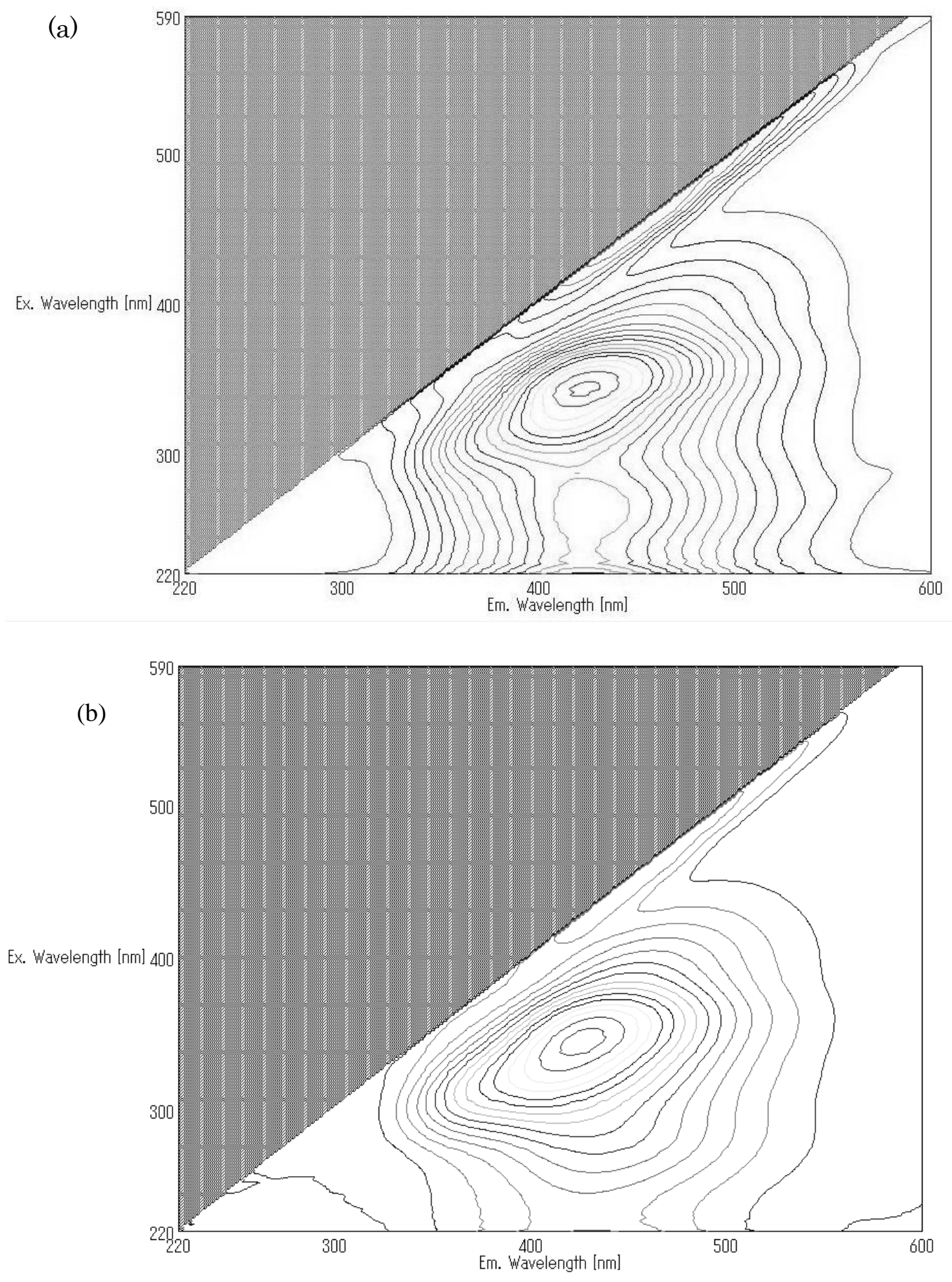

Fig. 2. Two-dimensional fluorescence spectra of HP (a) and LP (b) tholins (ammonia-water fraction). 
(a)

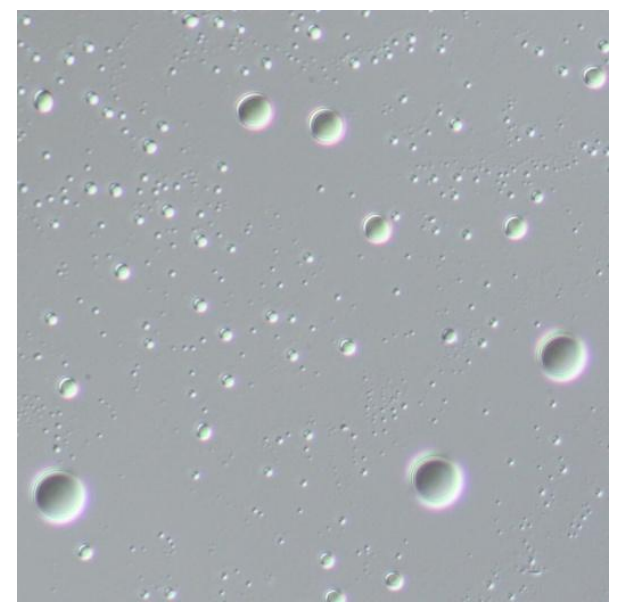

(b)

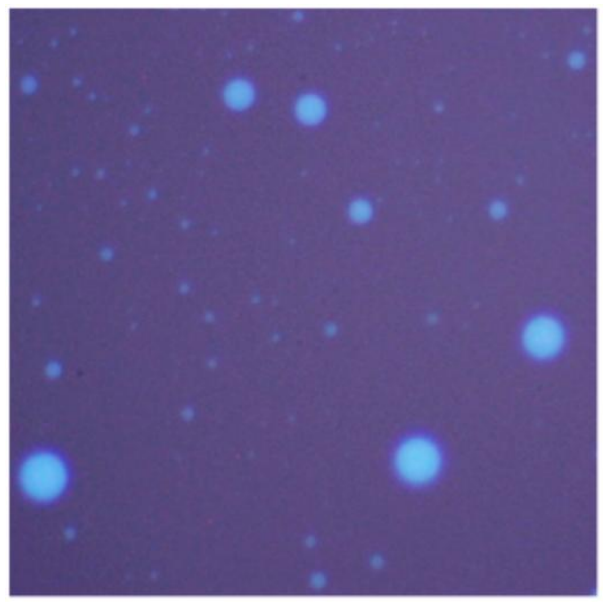

(c)

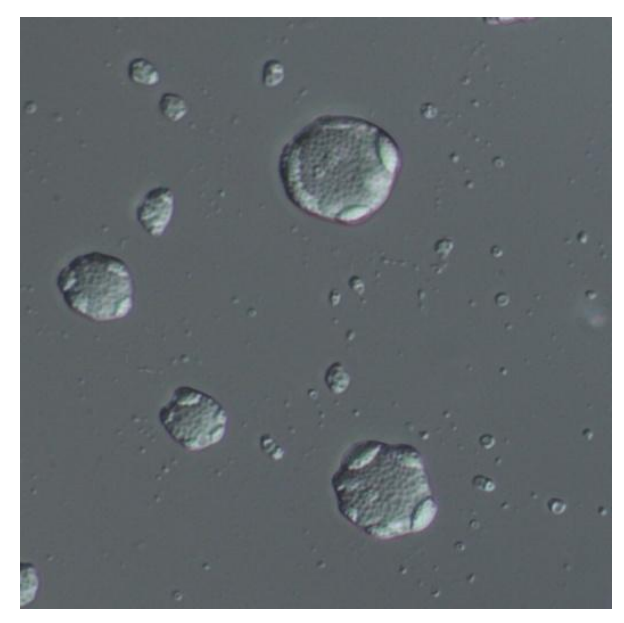

(d)

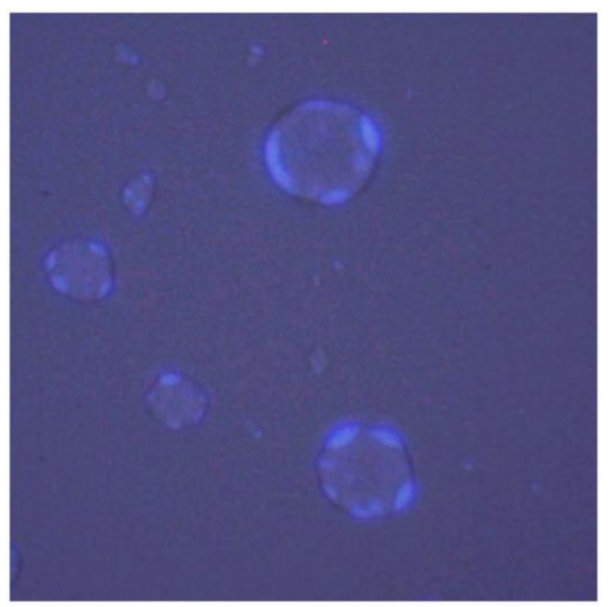

Fig. 3. (a) The DIC image when $10 \mathrm{mM}$ ammonia solution was added to tholins dried from a chloroform solution onto slide glass $(\times 400)$. (b) Fluorescence image of the same field.

(c)The DIC image when $10 \mathrm{mM}$ ammonia solution was added to the tholins dried from a hexane solution onto slide glass $(\times 400)$. (d) Fluorescence image of the same field. 
Table 1. Parameters of tholin synthesized by an electrical discharge

\begin{tabular}{|c|c|c|c|c|c|c|c|}
\hline Reference & Pressure & Gas mixture & Discharge & Temperature & System & Experiments & Solvents \\
\hline Khare et al (1986) & $200 \mathrm{~Pa}$ & $10 \% \mathrm{CH}_{4}, 90 \% \mathrm{~N}_{2}$ & DC glow & $300 \mathrm{~K}$ & Flow & GC/MS & $\mathrm{HCl}$ \\
\hline Sagan (1993) & $200 \mathrm{~Pa}$ & $10 \% \mathrm{CH}_{4}, 90 \% \mathrm{~N}_{2}$ & RF glow & $300 \mathrm{~K}$ & Flow & $\mu \mathrm{L} 2 \mathrm{MS}$ & \\
\hline Ehrenfreund (1995) & $20 \mathrm{~Pa}$ & $10 \% \mathrm{CH}_{4}, 90 \% \mathrm{~N}_{2}$ & DC glow & $300 \mathrm{~K}$ & Flow & Pyr-GC/MS & \\
\hline McKay (1996) & $10000 \mathrm{~Pa}$ & $10 \% \mathrm{CH}_{4}, 90 \% \mathrm{~N}_{2}$ & Spark & $300 \mathrm{~K}$ & Flow & Elementray analysis & $\begin{array}{l}\text { water, methanol, ethanol, ethylene } \\
\text { glycol, DMSO, hexane. benzene }\end{array}$ \\
\hline Coll (1999) & $\sim 200 \mathrm{~Pa}$ & $10 \% \mathrm{CH}_{4}, 90 \% \mathrm{~N}_{2}$ & DC glow & $300 \mathrm{~K}$ & Flow & GC/MS, FT-IR, SEM & Nitriles \\
\hline Sarker (2003) & $1000 \mathrm{~Pa}$ & $2 \% \mathrm{CH}_{4}, 98 \% \mathrm{~N}_{2}$ & AC glow & $195 \mathrm{~K}$ & Flow & ESI FT-ICR & methanol : acetonitrile 1:1 \\
\hline Hodyss (2004) & $1000 \mathrm{~Pa}$ & $2 \% \mathrm{CH}_{4}, 98 \% \mathrm{~N}_{2}$ & AC glow & $195 \mathrm{~K}$ & Flow & FS & water, acetonitrile \\
\hline Imanaka (2004) & $13 \mathrm{~Pa}-2300 \mathrm{~Pa}$ & $10 \% \mathrm{CH}_{4}, 90 \% \mathrm{~N}_{2}$ & RF glow & $300 \mathrm{~K}$ & Flow & $\begin{array}{l}\text { FT-IR, Elementary analysis, Raman, } \\
\text { UV-Vis, } \mu \text { L2MS }\end{array}$ & \\
\hline Smogyi (2005) & $1000 \mathrm{~Pa}$ & $5 \% \mathrm{CH}_{4}, 95 \% \mathrm{~N}_{2}$ & AC glow & $196 \mathrm{~K}$ & Flow & FT-ICR, MALDI-TOF, & methanol : acetonitrile 1:1 \\
\hline Szopa (2006) & $100 \mathrm{~Pa}$ & $10 \% \mathrm{CH}_{4}, 90 \% \mathrm{~N}_{2}$ & RF glow & $300 \mathrm{~K}$ & Flow & OES, SEM, Pyr GC/MS & \\
\hline McGuigan( 2006) & $160 \mathrm{~Pa}$ & $10 \% \mathrm{CH}_{4}, 90 \% \mathrm{~N}_{2}$ & RF glow & $300 \mathrm{~K}$ & Flow & $\mathrm{GC} \times \mathrm{GC}$ & \\
\hline Nguyen (2008) & $100 \mathrm{~Pa}$ & $10 \% \mathrm{CH}_{4}, 90 \% \mathrm{~N}_{2}$ & RF glow & $300 \mathrm{~K}$ & Flow & FT-ICR & $\mathrm{HCl}$ \\
\hline Carrasco (2009) & $100 \mathrm{~Pa}$ & $2,10 \% \mathrm{CH}_{4}, 98,90 \% \mathrm{~N}_{2}$ & RF glow & $300 \mathrm{~K}$ & Flow & SEM, FT-IR, APPI-TOFMS, CID & Methanol, toluene \\
\hline Neish $(2008,2009,2010)$ & $880 \mathrm{~Pa}$ & $2 \% \mathrm{CH}_{4}, 98 \% \mathrm{~N}_{2}$ & AC glow & $300 \mathrm{~K}$ & Flow & FT-ICR & ammonia, methanol : acetonitrile $1: 1$ \\
\hline Horst (2012) & $90 \mathrm{~Pa}$ & $\begin{array}{l}2 \% \mathrm{CH}_{4}, 96.2 \% \mathrm{~N}_{2}, 1.8 \% \mathrm{CO} \\
5 \% \mathrm{CH}_{4}, 93.2 \% \mathrm{~N}_{2}, 1.8 \% \mathrm{CO}\end{array}$ & RF glow & $330 \mathrm{~K}$ & Flow & GC/MS & Methanol \\
\hline $\mathrm{He}(2012)$ & $850 \mathrm{~Pa}$ & $5 \% \mathrm{CH}_{4}, 95 \% \mathrm{~N}_{2}$ & AC glow & $195 \mathrm{~K}$ & Flow & NMR & DMSO \\
\hline This research & $133 \mathrm{~Pa}, 26 \mathrm{~Pa}$ & $10 \% \mathrm{CH}_{4}, 90 \% \mathrm{~N}_{2}$ & RF glow & $300 \mathrm{~K}$ & Flow & FM, FS, FT-IR & chloroform, hexane \\
\hline
\end{tabular}


Table 2.

Boling point, melting point and dielectric constant of organic solvents

\begin{tabular}{|c|c|c|c|c|}
\hline Compound & Formula & $\begin{array}{l}\text { Freezing } \\
\text { Point (K) }\end{array}$ & $\begin{array}{l}\text { Boling } \\
\text { Point(K) }\end{array}$ & $\begin{array}{l}\text { Dielectric } \\
\text { Constant(D) }\end{array}$ \\
\hline \multicolumn{5}{|l|}{ Alkanes } \\
\hline 1-Pentene & $\mathrm{CH}_{3} \mathrm{CH}_{2} \mathrm{CH}_{2} \mathrm{CH}=\mathrm{CH}_{2}$ & 107.95 & 303.12 & 2.02 \\
\hline Isopentane & $\mathrm{CH}_{3} \mathrm{CH}\left(\mathrm{CH}_{3}\right) \mathrm{CH}_{2} \mathrm{CH}_{3}$ & 113.25 & 301 & 1.84 \\
\hline Isohexane & $\left(\mathrm{CH}_{3}\right)_{2} \mathrm{CHCH}_{2} \mathrm{CH}_{2} \mathrm{CH}_{3}$ & 119.45 & 333.42 & 1.88 \\
\hline 1-Hexene & $\mathrm{CH}_{3}\left(\mathrm{CH}_{2}\right)_{3} \mathrm{CH}=\mathrm{CH}_{2}$ & 133.35 & 336.64 & 2.05 \\
\hline \multicolumn{5}{|l|}{ Organohalogen compound } \\
\hline 2-Chlorobutane & $\mathrm{CH}_{3} \mathrm{CH}_{2} \mathrm{CHClCH}_{3}$ & 132.65 & 341.4 & 7.09 \\
\hline Chloroethane & $\mathrm{CH}_{3} \mathrm{CH}_{2} \mathrm{Cl}$ & 136.75 & 285.42 & 9.45 \\
\hline 3-Chloropropene & $\mathrm{CH}_{2}=\mathrm{CHCH}_{2} \mathrm{Cl}$ & 138.65 & 318.25 & 8.2 \\
\hline 1-Chloro-2-methylpropane & $\left(\mathrm{CH}_{3}\right)_{2} \mathrm{CHCH}_{2} \mathrm{Cl}$ & 142.85 & 342 & 6.49 \\
\hline 1-Chlorobutane & $\mathrm{CH}_{3} \mathrm{CH}_{2} \mathrm{CH}_{2} \mathrm{CH}_{2} \mathrm{Cl}$ & 150.05 & 351.59 & 7.39 \\
\hline 1-Chloropropane & $\mathrm{CH}_{3} \mathrm{CH}_{2} \mathrm{CH}_{2} \mathrm{Cl}$ & 150.35 & 319.75 & 9.45 \\
\hline 2-Chloropropane & $\mathrm{CH}_{3} \mathrm{CHClCH}_{3}$ & 155.97 & 308.89 & 9.82 \\
\hline \multicolumn{5}{|l|}{ Alcohol } \\
\hline 1-Propanol & $\mathrm{CH}_{3} \mathrm{CH}_{2} \mathrm{CH}_{2} \mathrm{OH}$ & 146.95 & 370.35 & 20.33 \\
\hline \multicolumn{5}{|l|}{ Ether } \\
\hline Ethyl ether & $\left(\mathrm{C}_{2} \mathrm{H}_{5}\right)_{2} \mathrm{O}$ & 149.35 & 307.7 & 4.34 \\
\hline Propyl ether & $\left(\mathrm{CH}_{3} \mathrm{CH}_{2} \mathrm{CH}_{2}\right)_{2} \mathrm{O}$ & 149.95 & 362.79 & 3.39 \\
\hline Isobutyl formate & $\mathrm{HCOOCH}_{2} \mathrm{CH}\left(\mathrm{CH}_{3}\right)_{2}$ & 178.65 & 371.55 & 6.41 \\
\hline Propyl formate & $\mathrm{HCOOCH}_{2} \mathrm{CH}_{2} \mathrm{CH}_{3}$ & 180.25 & 354 & 7.72 \\
\hline Propyl acetate & $\mathrm{CH}_{3} \mathrm{COOCH}_{2} \mathrm{CH}_{2} \mathrm{CH}_{3}$ & 180.65 & 374.7 & 6 \\
\hline \multicolumn{5}{|l|}{ Sulfur Compounds } \\
\hline Ethyl Sulfide & $\left(\mathrm{CH}_{3} \mathrm{CH}_{2}\right)_{2} \mathrm{~S}$ & 169.22 & 365.252 & 5.72 \\
\hline Methyl sulfide & $\left(\mathrm{CH}_{3}\right)_{2} \mathrm{~S}$ & 174.88 & 310.49 & 6.2 \\
\hline
\end{tabular}

Riddick, J. A. and Bunger, W. B. (1970) 
Table 3. Composition of Titan Atmosphere and their Boiling point and Freezing point (http://sci.esa.int/science-e/www/object/index.cfm?fobjectid=31187)

\begin{tabular}{llrrr}
\hline & Symbol & Amount & Freezing Point & \multicolumn{1}{c}{ Boiling Point } \\
\hline Major Constituents & & $(\%)$ & $(\mathrm{K})$ & $(\mathrm{K})$ \\
\hline Nitrogen & $\mathrm{N}_{2}$ & $87-99$ & 63.1 & 77.3 \\
Argon & $\mathrm{Ar}$ & $0-6$ & 83.8 & 87.3 \\
Methane & $\mathrm{CH}_{4}$ & $1-6$ & 90.6 & 111 \\
\hline Minor Constituents & & $(\mathrm{ppm})$ & $(\mathrm{K})$ & $(\mathrm{K})$ \\
\hline Hydrogen & $\mathrm{H}_{2}$ & 2000 & 14.0 & 20.3
\end{tabular}

\section{Hydrocarbons}

$\begin{array}{llrrr}\text { Ethane } & \mathrm{C}_{2} \mathrm{H}_{6} & 20 & 89.2 & 185 \\ \text { Acetylene } & \mathrm{C}_{2} \mathrm{H}_{2} & 4 & 190 & 191 \\ \text { Ethylene } & \mathrm{C}_{2} \mathrm{H}_{4} & 1 & 104 & 169 \\ \text { Propane } & \mathrm{C}_{3} \mathrm{H}_{8} & 1 & 85.5 & 231 \\ \text { Methylacetylene } & \mathrm{C}_{3} \mathrm{H}_{4} & 0.03 & 170 & 250 \\ \text { Diacetylene } & \mathrm{C}_{4} \mathrm{H}_{2} & 0.02 & 268 & 284\end{array}$

\section{Nitrogen Compounds}

Hydrogen Cyanide

$\mathrm{HCN}$

1

260

299

Cyanogen

$\mathrm{C}_{2} \mathrm{~N}_{2}$

0.02

245

252

Cyanoacetylene

$\mathrm{HC}_{3} \mathrm{~N}$

0.03

278

316

Acetonitrile

$\mathrm{CH}_{3} \mathrm{CN}$

0.003

228

355

\section{Oxygen Compounds}

\begin{tabular}{llrrr} 
Carbon Monoxide & $\mathrm{CO}$ & 50 & 68.1 & 81.6 \\
Carbon Dioxide & $\mathrm{CO}_{2}$ & 0.01 & 195 & 217 \\
\hline
\end{tabular}

